\title{
Reflexões sobre os impactos econômicos e tecnológicos na organização do trabalho em empresas de base tecnológica
}

Pedro Paulo de Andrade Júnior*

RESUMO - Este artigo tem como preocupação central discutir os impactos econômicos e tecnológicos na forma de organização do trabalho em empresas de base tecnológica. Utilizou-se, para análise empírica, os pontos comuns mais frequentes, em especial ao que se refere à organização do trabalho num ambiente inovador. Além disso, apresenta-se também uma revisão da literatura acerca da importância do desenvolvimento de empresas de base tecnológica na economia e identificam-se características que estimulam a criatividade e as inovações necessárias para desenvolver um ambiente criativo, inovador e adaptável às mudanças tecnológicas.

Palavras-chave: Impacto tecnológico. Organização do trabalho. Formação gerencial.

\section{INTRODUÇÃO}

O impacto da inserção de novas tecnologias tem sido observado em diversos aspectos do segmento de empreendimento de base tecnológica, já que tais tecnologias desencadeiam um conjunto de relações de transformações. Entre essas relações, percebe-se e destaca-se, como uma das mais importantes, o estreitamento entre a forma de organização do trabalho e o nível de inovações tecnológicas das empresas.

A tecnologia caracteriza-se como um processo contínuo e irreversível que pode provocar diversas alterações, tanto nas organizações quanto na sociedade em geral; criando-se, assim, uma forte interação entre ela, o ambiente social e a organização. Porter (2005) justifica essa colocação ao dizer, em sua análise estrutural da empresa, que a essência da formulação de uma estratégia competitiva está em relacionar uma organização ao seu meio ambiente e, uma vez que as forças externas em geral afetam todas as empresas, o ponto básico encontra-se nas habilidades dessas em lidar com tais forças.

Com base nisso, entende-se que, ao estudar os impactos econômicos e tecnológicos sobre a organização do trabalho em empresas de base tecnológica, devem-se contemplar tanto as forças internas relevantes (representadas pela gestão de pessoas, pelas formas de desenvolvimento do trabalho e pela melhoria ou não da qualidade de produtos e/ou serviços prestados), quanto as externas (como as relacionadas com os clientes: sua satisfação, a aceitação da tecnologia e a competitividade da empresa).

A opção por avaliar as empresas de base tecnológica baseia-se no fato de que esse

* Doutor em Engenharia de Produção pela Universidade Federal de Santa Catarina. É professor adjunto da Universidade Tecnológica Federal do Parará. Endereço eletrônico: pedropaulo@utfpr.edu.br. 
segmento vem exercendo um papel importante na economia, tendendo a crescer, cada vez mais. Aliás, essa é uma das tendências generalizadas nas economias modernas e desenvolvidas. Assim, compreender o que se passa no interior das empresas voltadas às atividades de base tecnológica, principalmente ao que se refere às inovações em seus procedimentos na forma de organização do trabalho, é indispensável para que se criem condições favoráveis à formação de uma mentalidade empreendedora melhor preparada para o mercado, voltada para a qualidade e para a busca de vantagens competitivas entre as empresas ligadas aos empreendimentos de alta tecnologia.

A discussão sobre os empreendimentos de base tecnológica nas pesquisas que se destinam à compreensão dos impactos econômicos e das inovações tecnológicas na organização do trabalho ainda é insuficiente; muitos estudos já foram realizados nesse sentido, no entanto, há poucas análises científicas em torno desses impactos sobre as empresas do segmento de base tecnológica, pois esses estudos concentram-se, em grande parte, nas empresas de produção de bens.

Desta forma, todos os aspectos abordados, inicialmente, visam encontrar as bases teóricas indispensáveis para o estabelecimento de relação entre tecnologia e organização do trabalho nas empresas. Vale salientar que não se trata de uma abordagem muito abrangente mas, somente, de uma aproximação àqueles aspectos que são relevantes para o desenvolvimento desse estudo.

Em seguida, procura-se estudar mais atentamente a inter-relação entre o processo de trabalho e inovação tecnológica, e sua influência na organização do trabalho, partindo-se para a identificação de como os impactos das tecnologias têm afetado a formação gerencial e a organização do trabalho, principalmente no segmento de empresas de base tecnológica. A discussão em torno das consequências advindas dos impactos das tecnologias na organização do trabalho nas empresas de base tecnológica é sintetizada nas considerações finais.

\section{METODOLOGIA}

Conforme teorização metodológica proposta por Yin (2005) e Miguel (2010), este trabalho desenvolve-se como uma pesquisa de natureza básica. A abordagem do problema acontece de maneira qualitativa. Os objetivos são analisados do ponto de vista exploratório. Em relação aos procedimentos técnicos, classifica-se como bibliográfica. Foi elaborado um levantamento teórico-conceitual sobre a abrangência do conceito de tecnologia e inovação, a importância das empresas de base tecnológica e a organização do trabalho na evolução tecnológica. O contexto deste trabalho conflui na criação de uma análise que possibilitou correlacionar e explicar o impacto da tecnologia no programa de formação gerencial. 
É importante ressaltar a carência de estudos integrativos de teorias preocupadas em analisar o impacto da tecnologia no programa de formação gerencial, por isso, a ausência de um estudo empírico que dê suporte às ideias aqui propostas, as quais surgiram de um estudo bibliográfico de diversos materiais. Portanto, há ainda um vasto caminho a ser percorrido para que o presente estudo alcance sua total plenitude bibliográfica, acadêmica e metodológica.

\section{A IMPORTÂNCIA DAS EMPRESAS DE BASE TECNOLÓGICA}

Nos últimos vinte anos, as Empresas de Base Tecnológica (EBT) vêm desempenhando um importante papel no desenvolvimento socioeconômico de diversos países. Tal fenômeno pode ser justificado pelas contribuições que estas organizações proporcionam, tais como: permitir aos países menos favorecidos realizar inovações em produtos e serviços de grande potencial; estimular o progresso da ciência e da tecnologia; gerar novas competências e qualificações; e estimular o empreendedorismo.

Para Andrade Júnior (2006), atualmente as EBT são reconhecidas, também, pela renovação econômica que proporcionam às regiões atingidas pelo enfraquecimento de setores tradicionais da economia, constituindo-se em alternativa estratégica para redirecionar as respectivas economias aos padrões vigentes de competitividade e comportamento. As EBT podem tirar proveito por intermédio das inter-relações, na melhoria da qualidade de bens e serviços, ou na redução de custos, exigindo a concepção e configuração de modelos mais competitivos e apropriados à realidade da região onde serão instaladas, sendo voltadas, em sua maioria, para atividades que requerem pesquisas constantes e tecnologia inovadora.

Destaca-se que as inovações tecnológicas alteram a forma de geração de riquezas, renda e emprego, por meio da superação de estruturas tradicionais de financiamento, gestão, produção e comercialização, promovendo uma aceleração na competição empresarial, impulsionando, dessa forma, o desenvolvimento de um país.

Desse modo, de acordo com Andrade Júnior (2011), surgiram no país cerca de dois mil e quinhentos empreendimentos de base tecnológica, nos últimos quinze anos, com atividades em setores mais especializados da informática, biotecnologia, mecânica de precisão, química fina, entre outros, contribuindo para o crescimento econômico e o fortalecimento regional com mais de 15.000 empregos gerados pelo movimento de incubadoras no Brasil, oferecendo suporte em áreas nas quais os novos empreendimentos encontravam-se carentes.

Em vista do exposto, observa-se que as incubadoras de empreendimentos tecnológicos constituem uma alternativa estratégica para impulsionar o desenvolvimento econômico e tecnológico das regiões onde atuam, aumentando as oportunidades de emprego, a geração de 
renda e diversificando bens e serviços por meio de condições favoráveis ao avanço da tecnologia que está na base das atividades deste tipo de empreendimento.

Considerando a intensificação do processo de globalização e, consequentemente, o aumento da competitividade nos mercados, as empresas precisam reforçar os elementos favoráveis aos seus processos de desenvolvimento, adequando-se, assim, aos desafios impostos pelo mercado neste cenário, buscando desse modo um melhor desempenho nas atividades que exercem.

Neste sentido, o fortalecimento de empreendimentos de tecnologias avançadas tende a se confirmar como uma estratégia compatível para enfrentar as exigências do mundo contemporâneo, em especial nos países em desenvolvimento. Assim, as EBT assumem importante papel no avanço econômico e tecnológico.

Entendida a abrangência da importância das empresas de base tecnológica, pode-se ter uma visão mais completa da organização do trabalho na evolução tecnológica.

\section{A ORGANIZAÇÃO DO TRABALHO NA EVOLUÇÃO TECNOLÓGICA}

O impacto da introdução de novas tecnologias tem sido observado em diversos aspectos nas empresas e na sociedade, não sendo diferente do segmento de alta tecnologia, proporcionando um conjunto de relação de transformações desencadeadas por tais tecnologias. Para Andrade Júnior (2002), uma dessas relações pode ser percebida e destacada: a forma de organização do trabalho com os níveis de inovações tecnológicas nas empresas força as mesmas a buscarem novas formas específicas de organização do trabalho.

A modernização tecnológica nos sistemas produtivos faz parte de todo um contexto capitalista, e seus efeitos na organização do trabalho vêm alimentando vários estudos. Tal debate tem gerado bastante controvérsia, atribuindo impactos negativos (desemprego, desqualificação e monotonia) e positivos (qualificação, ampliação das oportunidades de emprego, trabalho participativo e aumento de produtividade). Várias correntes foram seguindo e adicionando importantes contribuições ao assunto; no entanto, todas elas reconhecem que o desenvolvimento de novas tecnologias implica em repensar os processos de organização do trabalho e as qualificações requeridas.

Nesse contexto, pode-se colocar o avanço tecnológico como decorrente do esforço humano na procura de minimizar suas tarefas e de aperfeiçoar o produto ou serviço de seu trabalho. Segundo Rodrigues e Ornellas (1987), na sociedade industrializada o progresso técnico apresenta, pelo menos, três metas básicas: a redução do esforço de trabalho, o aumento da produtividade (ou seja, a obtenção de mais produtos com igual ou menor quantidade de trabalho) 
e a melhoria da qualidade do produto.

Como se vê, em qualquer das metas citadas por esses autores é evidente não só a forte vinculação entre tecnologia e trabalho, aparecendo a primeira como determinante do modo de execução e organização do segundo, mas também o objetivo de melhorar a eficácia da empresa. As novas tecnologias têm sido utilizadas exatamente para perseguir essas metas, e alguns resultados têm sido notados.

A não existência de políticas sólidas e efetivamente praticadas, no que se refere ao impacto de novas tecnologias no segmento tecnológico, torna sem efeito as intenções e os planos existentes (como, por exemplo, gerenciar o trabalho face à modernização tecnológica). Com relação a esse aspecto, Andrade Júnior (2002) chama a atenção para contradições entre o modelo de gestão adotado e o contexto ambiental e social, como: a) buscar absorver alta tecnologia sem investir na qualificação requerida; b) introduzir metas de aperfeiçoamento da qualidade, competitividade e flexibilidade, como a manutenção de políticas e processos preconizadores das relações de trabalho; c) implantar modelos que pressupõem integração de funções produtivas em sistemas de trabalho ainda fragmentados; d) divulgar políticas sem implantá-las.

Em suma, segundo os autores pesquisados, o desenvolvimento tecnológico pode apresentar vantagens e desvantagens, dependendo de sua aplicação e gerência. A tecnologia tem desempenhado importante papel dentro das organizações, com consequências para o trabalho desempenhado, para as tarefas, para as pessoas envolvidas e para a estrutura organizacional.

A fim de obter vantagem competitiva, a organização vê-se obrigada a encontrar meios de ensinar o seu contingente a gerar as informações e os conhecimentos necessários, levando à necessidade da empresa de elaborar programas específicos de formação gerencial.

\section{IMPACTO DA TECNOLOGIA NO PROGRAMA DE FORMAÇÃO GERENCIAL}

Em relação ao conjunto de transformações desencadeadas pelos impactos das novas tecnologias na organização do trabalho, deve-se atentar para a forma de reorganização das tecnologias de gestão de pessoas nas empresas, que as forçam a buscar novas formas de organização do trabalho e desenvolver novas formas de gerenciamento de pessoal.

Conforme Andrade Júnior (2006), o impacto da tecnologia pode ser percebido de duas formas diferentes na organização e na vida das pessoas: prejudicial, pois sugere um gasto de recursos, uma organização centralizada, a perda de liberdade pessoal e de dignidade, a desigualdade, o consumismo e o desemprego; ou benéfica, pois sugere maior liberdade pessoal, democracia participativa, mais tempo para recreação, maior conhecimento e melhoria na qualidade de vida. 
O mesmo autor, pesquisando sobre o impacto da tecnologia nas empresas, afirma que ambos os pontos de vista são justificados, sendo que a tecnologia pode: centralizar e descentralizar a autoridade dentro da empresa, aumentar e diminuir as oportunidades dos funcionários, permitir aos trabalhadores maior acesso à informação administrativa ou reforçar o controle administrativo, mudar ou estagnar a estrutura organizacional e, ainda, limitar ou aumentar a satisfação no trabalho.

A introdução de novas tecnologias tem forçado as empresas a confrontarem várias questões, cujas soluções sugerem que um novo tipo de gestor esteja surgindo neste meio. Cartee Júnior (2007) aponta várias questões que esse empreendedor terá que responder, como, por exemplo: quais decisões gerenciais com relação à implantação da automação podem ser tomadas no sentido de diminuir custos e maximizar benefícios? Como a gerência deve responder às demandas crescentes com relação à melhoria de qualidade de vida no trabalho, vistas as preocupações tradicionais com produtividade? E, ainda, como os gestores podem melhor compreender, moldar e controlar as mudanças associadas e não, simplesmente, encarar suas consequências como algo inevitável?

A essas questões, pode-se acrescentar a postura de agir com respeito e confiança. Assumir um compromisso com o bem-estar de cada participante do processo, reconhecendo que o pessoal é o recurso mais valioso das instituições e é fundamental para o sucesso de qualquer empresa de base tecnológica. Por exemplo: o gestor de empresas de base tecnológica deve estimular o pessoal a alcançar níveis cada vez mais altos de realização, articular e manter uma visão de futuro que possa ser assimilada pelo pessoal, capacitando-o a relacionar sua responsabilidade com o alcance das metas de organização e, também, manter uma força de trabalho formada por especialistas treinados e capazes de responder às rápidas mudanças provocadas pelo desenvolvimento tecnológico e econômico.

Percebe-se, nitidamente, que o impacto da tecnologia pode repercutir na organização do trabalho nas empresas de base tecnológica, tanto em aspectos positivos como negativos. O primordial é que a organização adote uma filosofia gerencial que possa beneficiar-se e/ou adaptar-se com as mudanças provocadas pelas novas tecnologias.

Para Andrade Júnior (2009), o momento atual pede profissionais da área de base tecnológica em sintonia com as novas tecnologias, e estes devem possuir algumas características, tais como: serem flexíveis às mudanças, empreendedores, criativos, críticos, intuitivos, éticos, capazes de trabalhar em equipe e com as novas tecnologias. Esses atributos necessitam de um ambiente de trabalho motivador por intermédio, por exemplo, de cursos de treinamentos e reciclagem permanentes, capazes de aprimorar os empreendedores e gestores de empreendimentos 
de base tecnológica com uma educação adequada.

\section{CONSIDERAÇÕES FINAIS}

Procurou-se, nesse artigo, mostrar aspectos conceituais de inovação tecnológica e a importância das empresas de alta tecnologia. Tais informações tiveram a função de esclarecer ao leitor as possíveis relações entre inovação tecnológica e organização do trabalho nas EBT, além de apresentar uma visão geral sobre o tema em estudo.

O crescimento econômico e tecnológico observado na última década exige que as empresas de base tecnológica adotem uma postura empreendedora e uma estratégia de inovação, incorporando o processo de organização do trabalho que proporcione avanços para a empresa e seja capaz de gerar competitividade, melhoria da qualidade e menores custos.

Nota-se que os principais objetivos perseguidos pelas empresas, ao adotarem inovações tecnológicas, variam bastante, mas, geralmente, são de natureza aquisitiva e procuram ativamente a inovação como forma de melhorar a agilidade do atendimento aos clientes, assim como modernizar o processo, aproveitar melhor os seus recursos e explorar novos segmentos de mercado.

Neste sentido, identifica-se uma forte vinculação entre inovação tecnológica e organização do trabalho nas EBT, aparecendo a primeira como determinante do modo de execução e apresentação da segunda, mas também com o objetivo de melhoria da eficácia da empresa. Além disso, o impacto da tecnologia tem forçado à redefinição de algumas funções, repercutindo seriamente na organização do trabalho.

Verifica-se, também, que os empreendimentos de base tecnológica que estão inseridos em um contexto de mudanças promovem características para desenvolver, na organização, um ambiente criativo e inovador a fim de beneficiarem-se com o processo desencadeado por tais tecnologias.

Levando-se em conta o que foi observado, a EBT que deseja obter sucesso em função do impacto tecnológico na organização do trabalho precisa adaptar sua forma gerencial às condições exigidas em um ambiente em constante processo de mudanças, utilizando-se de inovação e criatividade, bem como, possuir elevado grau de relacionamento com todos os envolvidos nesse ambiente de contínua transformação.

Para finalizar, acredita-se que a contribuição mais importante desse trabalho está em evidenciar o papel relevante que as inovações tecnológicas têm na organização do trabalho em instituições voltadas aos empreendimentos de base tecnológica e a necessidade de adaptação dessas empresas ao novo ambiente, de forma criativa e inovadora. 


\section{REFERÊNCIAS}

ANDRADE JÚNIOR, P. P. The brazilian experience in the development of companies of technological high in incubators. Rio de Janeiro: Aped, 2011.

ANDRADE JÚNIOR, P. P. O desafio do empreendedor em empresas de base tecnológica em incubadoras. São Paulo: Reverbo, 2009.

ANDRADE JÚNIOR, P. P. Modelo bidimensional de avaliação da capacidade de superação das dificuldades de empresas de base tecnológica em incubadoras: um estudo multicaso. 245 f. Tese (Doutorado em Engenharia de Produção) - Programa de Pós-Graduação em Engenharia de Produção, Universidade Federal de Santa Catarina, Florianópolis, 2006.

ANDRADE JÚNIOR, P. P. Os impactos de novas tecnologias na organização do trabalho em empresas do setor de serviços. Revista Alcance, Itajaí, n. 4, p. 47-55, 2000.

CARTEE JÚNIOR, L. D. Is library automation producing a new kind of manager. Journal of Library Administration, Canada, v. 13, n. 1/2, 2007.

MIGUEL, P. A. C. (Org.). Metodologia de pesquisa em engenharia de produção e gestão de operações. Rio de Janeiro: Elsevier, 2010.

PORTER, M. Estratégia Competitiva. Rio de Janeiro: Campus, 2005.

RODRIGUES, I. P. da F.; ORNELLAS, E. Influência da tecnologia na estrutura organizacional e eficácia das empresas. Revista de Administração de Empresas, São Paulo, v. 22, n. 2, p. 25-34, abr./jun. 1987.

YIN, R. K. Estudo de caso: planejamento e métodos. 3. ed. Porto Alegre: Bookman, 2005. 